\title{
FILM COOLING OVER A CONCAVE SURFACE THROUGH TWO STAGGERED ROWS OF COMPOUND ANGLE HOLES
}

\author{
I-Chien Lee, Yun-Chung Chang, Pei-Pei Ding, and Ping-Hei Chen*
}

\begin{abstract}
Experimental results of film cooling effectiveness over a concave surface with two staggered rows are presented by employing transient liquid crystal thermography. Four different discrete hole configurations are used for the injection of jet flow, including a straight circular hole configuration with a spanwise injection angle $(\beta)$ of $0^{\circ}$ and three forward-expanded hole configurations with $\beta=0^{\circ}, 45^{\circ}$ and $90^{\circ}$ respectively. In all test models there are two staggered rows of discrete holes with streamwise injection angle $(\gamma)$ of $35^{\circ}$. Blowing ratios $(M)$ are $0.5,1.0$, and 2.0 . The effects of blowing ratio, hole expanded angle, and injection angle orientation on film cooling performance are investigated. The jet flow with $M=0.5$ is fairly uniform along the wall surface. The lift-off phenomenon can be found in the jet flow with $\beta=0^{\circ}$ for both cases of simple and compound angles at $M=1.0$ and also exists among all test cases at $M=2.0$ except for $\beta=90^{\circ}$. The lift-off effect results in a decrease in both $\bar{\eta}$ and $\bar{h} / h_{0}$. At $\beta=0^{\circ}$, the jet flow with a forward-expanded hole gives higher $\bar{\eta}$ and lower $\bar{h} / h_{0}$ than a simple angle hole. At a fixed blowing ratio, the jet flow with compound angle holes has lower $\bar{q} / q_{0}$ and thus provides better wall protection than that with simple angle holes. In the present study, the compound angle with $\beta=0^{\circ}$ at $M=2.0$ provides the best film-cooling protection over the concave surface among all the test configurations.
\end{abstract}

Key Words: film cooling, concave surface, compound angle.

\section{INTRODUCTION}

The purpose of using film cooling is to protect a turbine blade from exposure to excessive inlet mainstream temperature. It becomes essential to provide effective film cooling protection over the turbine blade surface to extend its life duration. There are many studies that have proposed various geometrical arrangements of injection holes to enhance film-cooling effectiveness. These geometrical arrangements of injection holes include injection angle, pitch-todiameter ratio, length-to-diameter ratio, hole shape, number of rows of injection holes, and orientation of holes with respect to mainstream.

Goldstein et al. (1974) demonstrated that expanding holes gives better film cooling performance

*Corresponding author. (Tel: 886-2-23670781; Fax: 886-223631755; Email: phchen@ @tu.edu.tw)

The authors are with the Department of Mechanical Engineering, National Taiwan University, Taipei, Taiwan 106, R.O.C. than cylindrical round holes over a flat plate. Chen et al. (1998) observed a similar trend for film cooling with conical holes on a flat plate. In addition, Schmidt et al. (1996) and Sen et al. (1996) reported the combined influences of expanded holes configuration and compound angle injection on flat plate film cooling. Ekkad et al. (1997a, 1997b) studied the effects of blowing ratio and compound angle injection over a flat surface when using both air and $\mathrm{CO}_{2}$ as coolants. Yu et al. (2002) investigated the effect of diffusion shaped holes on film cooling performance over a flat plate. In their studies, it was found that thermal load over the tested piece is reduced by 20 to $30 \%$ if the straight circular hole is replaced by hole geometry with a combined forward and lateral diffusion.

Experimental investigation of the discrete holes film cooling characteristics over curved surfaces by Ko et al. (1986) showed that the film coverage of a concave surface is wider than that of a convex surface along the spanwise direction. Schwarz and 
Goldstein (1989) investigated film cooling over a concave surface through a row of straight circular holes. Their measured results showed that the film cooling characteristics over a concave surface through a row of discrete circular holes are similar to those for a slot film cooling over a flat plate except for cases with low blowing rates and weak wall curvature. Schwarz et al. (1991) also investigated experimentally film-cooling performance over a convex surface. Their results show that the lift-off phenomenon of coolant jets results in a decrease in film cooling effectiveness with increase in blowing ratio over convex surface. Goldstein and Stone (1997) employed the same test section as that used by Schwarz et al. (1991) to conduct a study on film cooling over both concave and convex surfaces. They used the flow visualization of an ammonia vapor injection system to observe the lift-off phenomenon of jet flow. They found that the jet flow gently flew into the boundary layer and the film cooling effectiveness increased with blowing ratio at low blowing rate of 0.5 . As the blowing rate was increased to 0.75 , the lift-off phenomenon of the jet flow appeared. A further study was discussed by Chen et al. (2001). They used transient liquid crystal thermography for conducting film cooling measurements on one row of simple hole and expanded-hole configurations. The results show that the compound angle injection provides higher film effectiveness than the simple angle injection while the forward-expanded hole injection has the best performance on both concave and convex surfaces.

Le Brocq et al. (1973), Jubran and Brown (1985), and Ligrani et al. (1994) reported film cooling through two rows of holes. Le Brocq et al. (1973) concluded that film cooling for a staggered arrangement of holes was better than that for an in-line arrangement. Jubran and Brown (1985) reported on the effects of hole spacing, row spacing and inclined angle of injection holes on film cooling effectiveness. Ligrani et al. (1994) provided a detailed description of the development of flow downstream of two staggered rows for a case where the secondary flows were ejected from holes with compound angle orientations on a flat plane. They showed that the compound angle injection configuration provides a much better film cooling protection than a simple angle injection configuration.

Nevertheless, few studies are to be found providing detailed film cooling effectiveness distributions over a concave surface with compound-angle injection through two staggered rows of forward-expanded holes. Since the flow passage between two neighboring turbine blades is highly curved, the effect of pressure gradient in the mainstream on film cooling performance should be taken into account. Thus, the present work aims at obtaining the heat

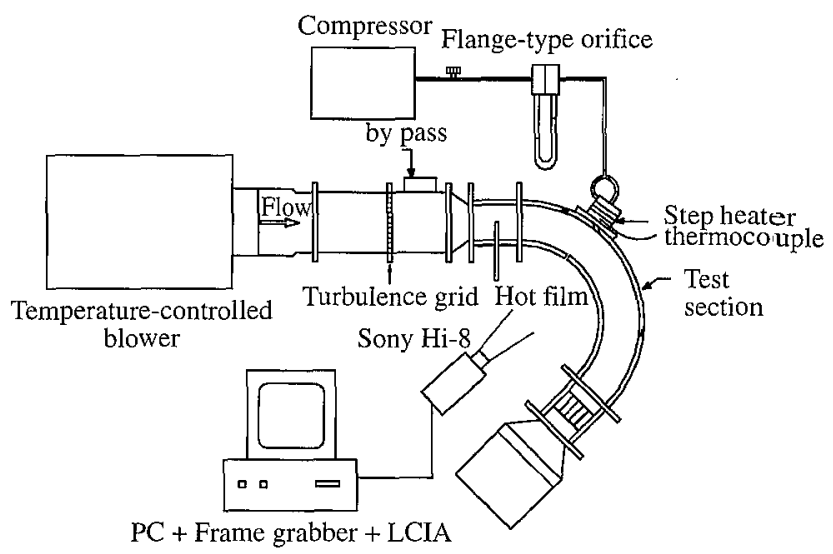

Fig. 1 Schematic view of test facility

transfer coefficient and the cooling effectiveness distributions over a concave surface with ejected flow through two staggered rows of forward-expanded holes by using a transient liquid crystal thermography.

\section{EXPERIMENTAL APPARATUS AND PROCEDURES}

The present test facility is the same as the one used by Chen et al. (2001) except that a straight test section is replaced by a curved test section. Transient liquid crystal thermography (Yu et al., 2002) is used to obtain both film cooling effectiveness and heat transfer coefficient. Detailed descriptions of the experimental apparatus and measuring technique can be found in the papers of Chen et al. (2001b) and Yu et al. (2002).

The experimental test facility consists of a wind tunnel with a temperature-controlled blower, a secondary flow system with a heating device, and an image capture and analysis system, as shown in Fig. 1. In this study, a hot film anemometer (Dantec, Flow Meter $54 \mathrm{~N} 60$ ) is used to measure the mainstream velocity. The turbulent intensity and the boundarylayer velocity are measured by the hot-wire anemometer (TSI IFA-100) with probes (TSI 1210-T1.5, TSI 1218-T1.5).

The secondary flow was heated up to an elevated temperature by a heating device. Both mainstream and injected flows were be diverted into the test section simultaneously when the temperatures of both flows were heated to the desired values. Ireland and Jones, (1987) showed that the response time of the liquid crystal change is only a few milliseconds. The transient temperature response histories of mainstream and secondary flow are measured by T-type thermocouples with a typical time response of 1 millisecond and recorded by a data logger (Gulton 
Table 1 Test configurations used in the present study

\begin{tabular}{cccclc}
\hline Models & Injection hole & $\gamma$ & $\beta$ & & $M$ \\
\hline Configuration-A & Straight circular hole & $35^{\circ}$ & $0^{\circ}$ & Simple-hole injection & 0.5, \\
Configuration-B & $8^{\circ}$ forward-expanded hole & $35^{\circ}$ & $0^{\circ}$ & Compound-angle injection & 1.0, \\
Configuration-C & $8^{\circ}$ forward-expanded hole & $35^{\circ}$ & $45^{\circ}$ & Compound-angle injection & 2.0 \\
Configuration-D & $8^{\circ}$ forward-expanded hole & $35^{\circ}$ & $90^{\circ}$ & Compound-angle injection & \\
\hline
\end{tabular}

Rustrak, Rustrak-Ranger II).

The curved test section has a cross sectional area of $100 \mathrm{~mm} \times 50 \mathrm{~mm}$ and a bend of $135^{\circ}$. The radius of curvature of the curved surfaces in the test section is $216 \mathrm{~mm}$. In the present study, four test pieces with different geometric arrangements of injection holes are used. There are two staggered rows of discrete injection holes on the each test piece. A summary of the geometric configurations of injection holes is given in Table 1, and a schematic view of shaped hole geometry is given in Fig. 2. All test pieces are made of Plexiglas. Configuration $\mathrm{A}$ is the one with straight cylindrical holes and a spanwise injection angle $(\beta)$ of $0^{\circ}$. Configuration $\mathrm{A}$ is a so-called simple hole injection configuration. For configurations $\mathrm{B}, \mathrm{C}$ and $\mathrm{D}$, however, there is a forward expanded angle of $8^{\circ}$ at the exit of cylindrical holes and a spanwise injection angle of $0^{\circ}, 45^{\circ}, 90^{\circ}$, respectively. For all four configurations, the inlet hole diameter $(d)$ is $5 \mathrm{~mm}$, the streamwise injection angle $(\gamma)$ is $35^{\circ}$, the lengthto-diameter ratio $(L / d)$ is 4.0 , the pitch-to-diameter ratio $(P / d)$ for both rows is 3.0 , the distance between centerlines of the first row and the second row is $4.0 d$, and the curvature $(2 r / d)$ is 86.5 . The image processing system includes a SONY Hi8 video camera, a frame grabber, and an image processing software LCIA V3.0 (Liquid Crystal Image Analyzer, Version 3.0 ). The image resolution on the test section area is $110 \times 40$ pixel.

The current study employed transient liquid crystal thermography ( $\mathrm{Yu}$ et al., 2002) to determine both film cooling effectiveness and heat transfer coefficient. An efficient method to improve data reduction on the transient liquid crystal thermography (Chen et al., 2001a) was used too. A curved copper plate with the same curvature as the test piece was used to calibrate color changes of liquid crystals with measured temperatures. The copper plate is coated with a layer of liquid crystal on the surface facing the test section and is attached with a heater on the opposite surface of copper plate. The copper plate is tightly installed on the test surface. For temperature calibration, both transient color changes in liquid crystals and temperature changes of the copper plate were recorded after the copper plate was heated by the attached heater. The calibrated temperature of
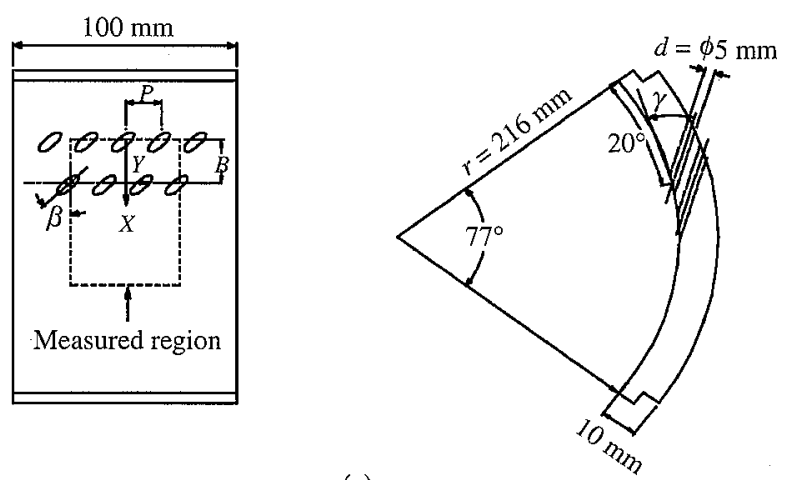

(a)
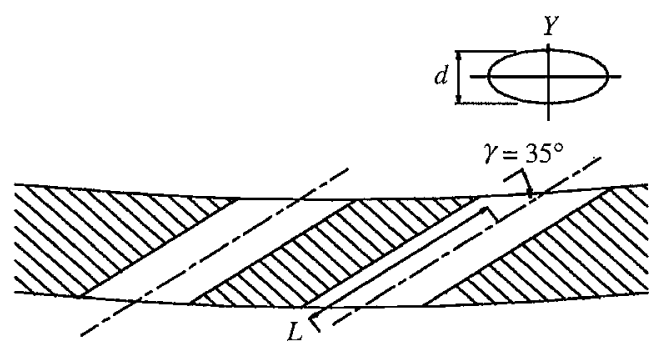

(b)

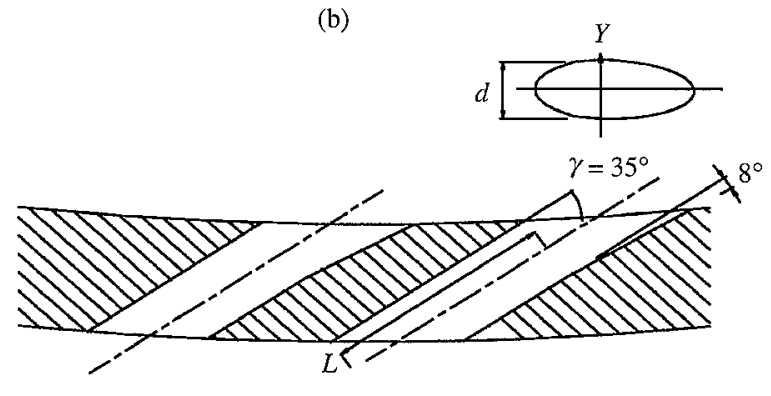

(c)

Fig. 2 The geometry: (a) test pieces, (b) two rows of circular straight holes, (c) two rows of forward-expanded holes

the liquid crystal in the present work was found to be $32.9^{\circ} \mathrm{C}$ for Green color displayed by liquid crystal.

\section{OPERATING CONDITIONS AND EXPERIMENTAL UNCERTAINTY}

The required blowing ratio in the current work was obtained by varying the velocity of jet flow at a mainstream velocity $\left(u_{m}\right)$ of $9.0 \mathrm{~m} / \mathrm{s}$ at the mid-point of the height of the duct with a distance of $50 \mathrm{~mm}$ 
downstream of contraction. The mainstream Reynolds number $\left(R e_{d}\right)$ is 2300 and the mainstream turbulence is $3.8 \%$. Measurements are conducted at blowing ratios $(M)$ of $0.5,1.0$ and 2.0 . The density ratio $\left(\rho_{c} / \rho_{m}\right)$ is 0.98 . The ratio of boundary layer displacement thickness to injection hole diameter $\left(\delta_{1} / d\right)$ is 0.16 at the position $(X, Y)$ of $(-4 d, 0)$ on the first row.

Uncertainty analysis, with $95 \%$ confidence level, on the measured parameters, was conducted by the method proposed by Kline and McClintock (1953). The factors resulting in the uncertainties of $h$ and $\eta$ are the mainstream temperature, the coolant temperature, the initial temperature, and the tested time. The total uncertainties of $\eta$ due to the four described factors are around $10.1 \%$ of their nominal values $(\eta=0.16)$, respectively. Furthermore, the uncertainties for the Reynolds number, blowing ratio, mainstream turbulence intensity and boundary layer displacement thickness are $3.4 \%, 2.8 \%, 4.3 \%$, and $5.6 \%$, respectively.

\section{RESULTS AND DISCUSSION}

\section{Comparison with Previous Studies}

Figure 3 shows a comparison of spanwise averaged film cooling effectiveness $(\bar{\eta})$ obtained in the study by Chen et al. (2001b) for one-row injection with that obtained in the present study for two rows of injection. Both studies utilize the same hole configuration $(\gamma, \beta, P / d, 2 r / d)$ but different row numbers of jet flow injection. They investigated the film cooling performance on curved walls with a five-hole single row. Note that the streamwise coordinate is measured from the center of the downstream row for the case of two-row injection. The comparison on $\bar{\eta}$ in Fig. 3 shows that film cooling effectiveness is significantly raised by adding one more row of injection at all blowing ratios of $0.5,1.0$ and 2.0 , particularly for cases with higher blowing ratios. In the measured region, the film cooling effectiveness is more than doubled by adding one more staggered row of injection at a blowing ratio of 2.0 . The film cooling effectiveness increases with blowing ratio beyond the locations at $X / d \approx 6.5$ for one-row injection and at $X / d \approx 2.8$ for two-row injection. It seems that the staggered arrangement of two injection rows reduces the effect of the lift-off phenomenon of ejected jet flows on film cooling near the injection holes at high blowing ratio. It is due to the fact that injection flow through the first row travels farther than that through the second row. With a staggered row arrangement, the injection flow through the first row is not directly affected by ejected flow of the second row, and is already bent by the mainstream towards the wall

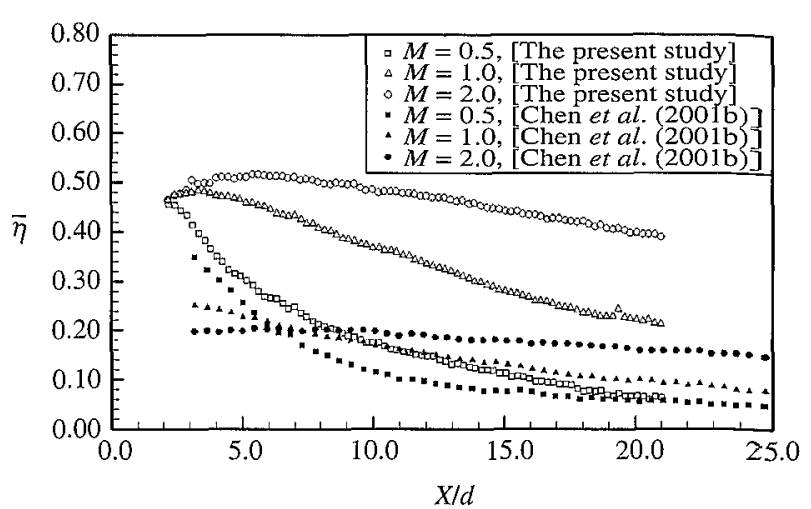

Fig. 3 Comparison with prior measured results of the spanwise averaged film cooling effectiveness $(\bar{\eta})$

surface to provide better protection, even in a region at a short distance downstream of the second row at high blowing ratio. On comparison at the same blowing ratio $(M)$, the jet flow of the staggered rows offered higher total mass flow rate than did a single row. Therefore, the spanwise averaged film cooling effectiveness $(\eta)$ of this study is higher than that of the single row (Chen et al., 2001b).

\section{Detailed Film Cooling Effectiveness Distribution}

The detailed distribution of film cooling effectiveness $(\eta)$ at blowing ratios $0.5,1.0$ and 2.0 for four types of hole configurations are respectively shown in Fig. 4.

At low blowing ratio of 0.5 , the film cooling effectiveness $(\eta)$ is relatively high in the near-hole region along the streamwise direction, as shown in Fig. 4(a). It means that the jet flow is fairly uniform close to the wall surface. For 0 deg. spanwise injection angle, the lateral distribution of film cooling effectiveness for injection with compound angle (configuration B) shows no obvious difference compared to that of injection with single angle (configuration A). For $45 \mathrm{deg}$. spanwise injection angle (configuration $\mathrm{C}$ ), the lateral component of moment of the jet flow widens the lateral cooling film coverage. As for $90 \mathrm{deg}$. spanwise injection angle (configuration D), the collision of the lateral jet flow with the streamwise mainstream results in aerodynamic loss and covers a comparatively short distance downstream of injection.

As the blowing ratio is increased to 1.0 , the compound angle effect is very obvious as shown by comparison of the four configurations in Fig. 4(b). The spread-out effect of the compound angle in the lateral direction widens the lateral cooling film coverage. The injection with compound angle also provides longer protection to the wall surface than the one with single angle, downstream in the 

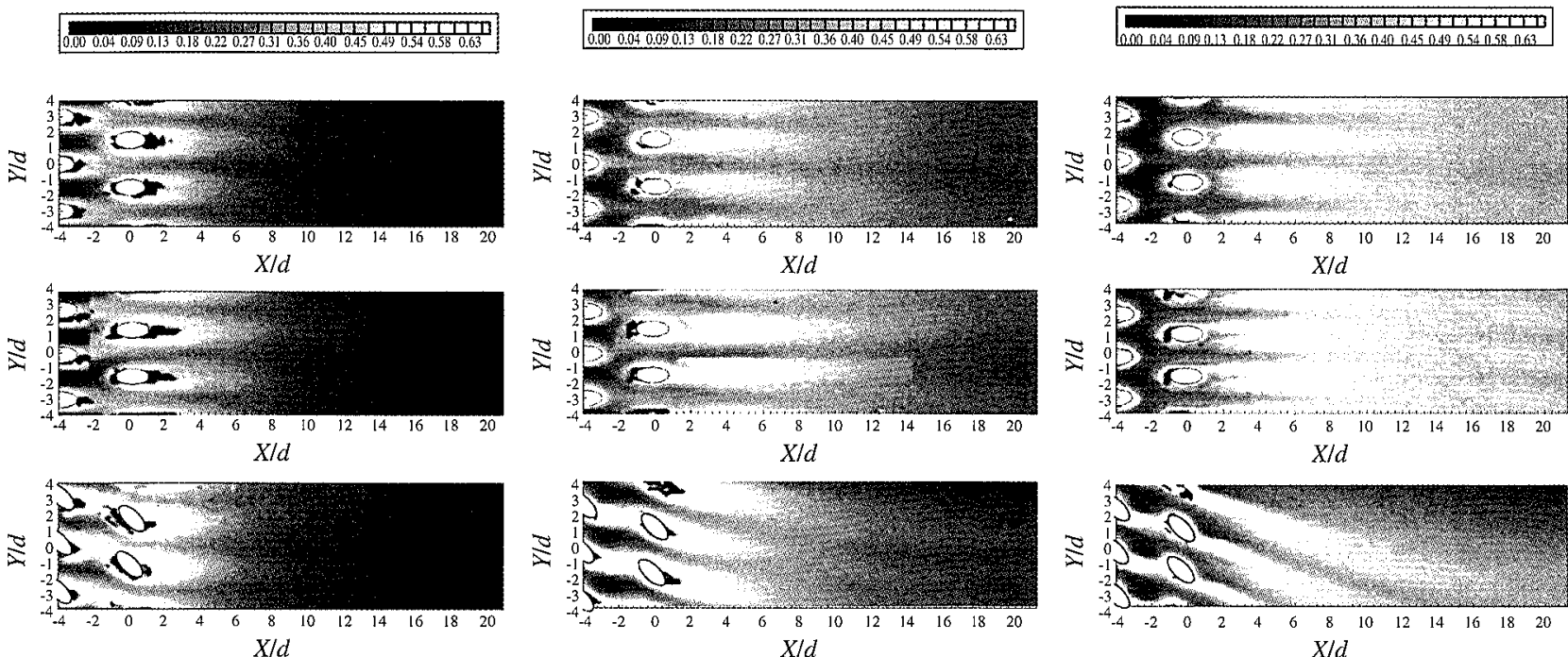

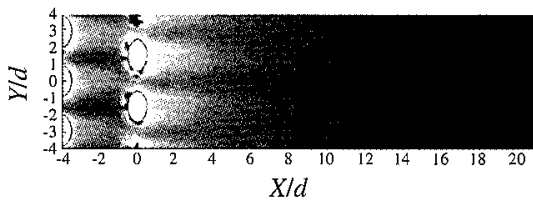

(a)

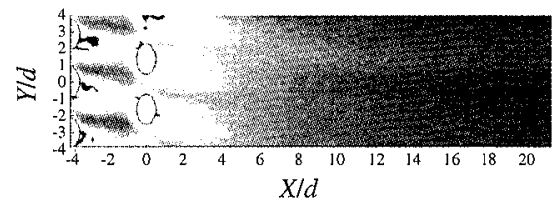

(b)

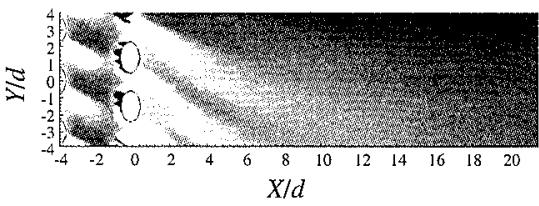

(c)

Fig. 4 The detailed distribution of film cooling effectiveness ( $\eta$ ) at various hole configurations: (a) $M=0.5,(\mathrm{~b}) M=1.0$, (c) $M=2.0$

streamwise direction. It can be termed the close-wall effect of compound angle.

As the lift-off effect was described earlier by Goldstein and Stone (1997), they visualized the jet flow for a row of holes with injection angles of 15, 25 and $45 \mathrm{deg}$. along the concave surface. They showed that jet flow was lifting away from the wall on the concave surface when the blowing ratio was increased to 0.75. Berhe and Patankar (1999) mentioned that pairs of counter-rotating vortices would appear at high blowing ratios. This phenomenon causes the decrease in $\eta$ because the pairs of counter-rotating vortices lift the injection flow away from the surface and enter the hot mainstream from the surroundings to the surface. In this study, the lift-off effects of configuration $A$ and configuration $B$ occur near the exit holes of the first row at the blowing ratio of 1.0 and decreases $\eta$, as shown in Fig. 4(b), but the same does not appear for configuration-C and configuration-D. The jet flows of configuration A and configuration $B$ have mild liftoff effects on the downstream of the second row, as shown in Fig. 4(b). For 45 deg. and 90 deg. spanwise injection angles, the cooling film coverage is wider in the lateral direction and shorter in the streamwise direction than the one of $0 \mathrm{deg}$. spanwise injection angle.

As the blowing ratio reaches 2.0 , the lift-off effects of configurations $\mathrm{A}$ and $\mathrm{B}$ are obvious on both rows, as shown in Fig. 4(c). The effect of the compound angle injection creates more uniform effectiveness on the whole surface in comparison with the effect provided by single angle injection. For $45 \mathrm{deg}$. and $90 \mathrm{deg}$. spanwise injection angles, the cooling film coverage of the blowing ratio of 2.0 is more narrow in the lateral direction and longer in the streamwise direction than the one of $M=$ 1.0. The jet flows of configuration $C$ have mild lift-off effects on the downstream of the second row, as shown in Fig. 4(c).

\section{Spanwise Averaged Film Cooling Effectiveness $(\bar{\eta})$}

Spanwise averaged film cooling effectiveness $(\bar{\eta})$ measured downstream $(X / d)$ from 2.0 to 21.0 , at various hole configurations, is shown in Figs. $5(\mathrm{a}, \mathrm{b}, \mathrm{c})$.

In Fig. 5(a), the $\bar{\eta}$ value decreases along the streamwise direction of the mainstream at low blowing ratio of 0.5 . It means that the jet flow is fairly uniform along the wall surface and is kept in the boundary layer. The spanwise averaged film cooling effectiveness $(\bar{\eta})$ of configuration $\mathrm{B}$ is higher than the one of configuration A over the whole measured region. For the 45 deg. spanwise injection angle, the flow provides a spanwise component of moment flux and has higher $\bar{\eta}$ value than the others in the near hole region, $X / d<$ 3.3. For the $90 \mathrm{deg}$. spanwise injection angle, the spanwise averaged film cooling effectiveness $(\bar{\eta})$ is lower than others over the whole measured region.

As the blowing ratio is increased to 1.0 , the 


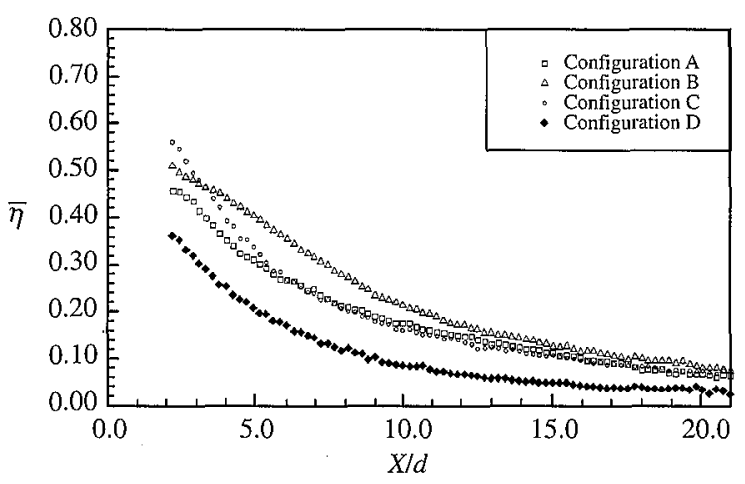

(a) $M=0.5$

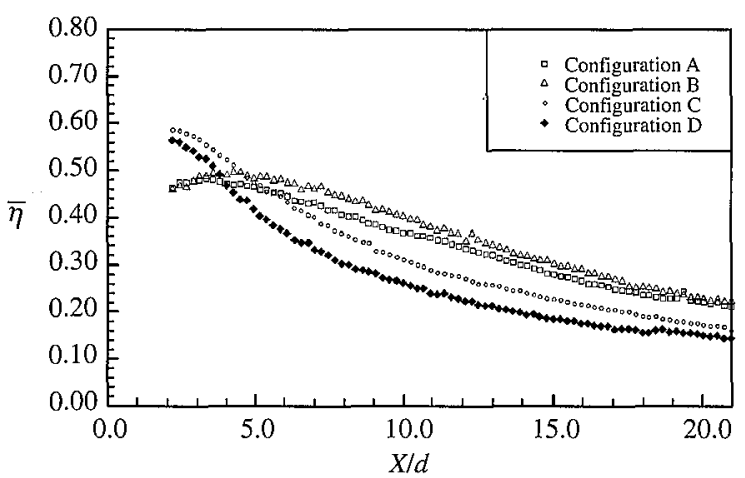

(b) $M=1.0$

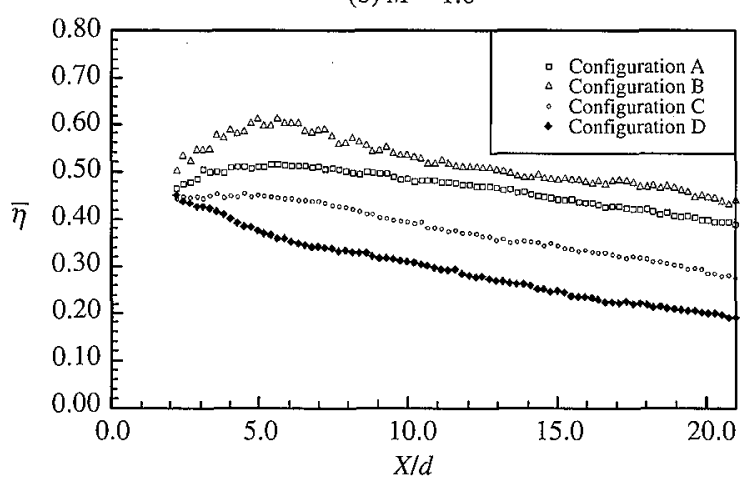

(c) $M=2.0$

Fig. 5 Streamwise distributions of spanwise averaged film-cooling effectiveness $(\bar{\eta})$ at various hole configurations: (a) $\mathrm{M}=0.5$, (b) $M=1.0$, (c) $M=2.0$

lift-off effect of jet flow causes lower $\bar{\eta}$ value for $X /$ $d<3.4$ on configuration $\mathrm{A}$ and for $X / d<4.6$ on configuration $\mathrm{B}$ as shown in Fig. 5(b). When $X / d>5.0$, configuration $\mathrm{B}$ with compound angle gives the largest $\bar{\eta}$ value as compared to other hole configurations. For $45 \mathrm{deg}$. and $90 \mathrm{deg}$. spanwise injection angles, $\bar{\eta}$ values decrease along the streamwise direction of the mainstream.

At high blowing ratio of 2.0, the lift-off effect of jet flow causes lower $\bar{\eta}$ value for $X / d<5.4$ on configuration $\mathrm{A}$, for $X / d<5.0$ on configuration $\mathrm{B}$, and for $X / d<4.5$ on configuration $C$, as shown in Fig. 5(b). Configuration $B$ with compound angle gives the largest $\bar{\eta}$ value as compared to other hole

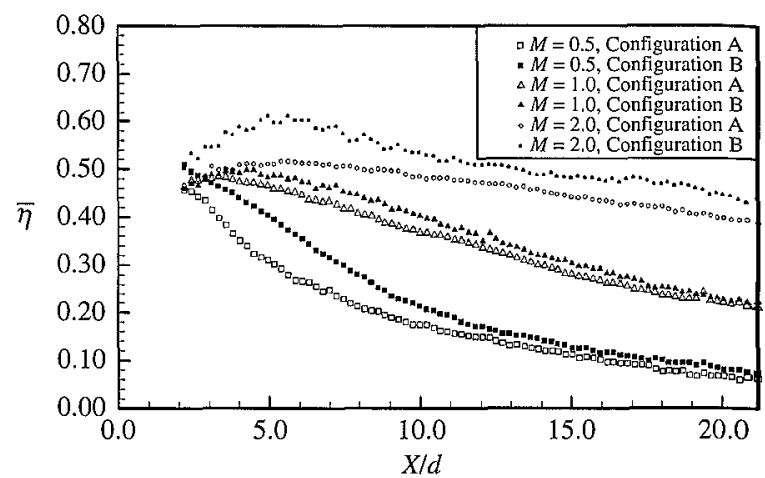

(a) Configuration $\mathrm{A}$ and $\mathrm{B}$

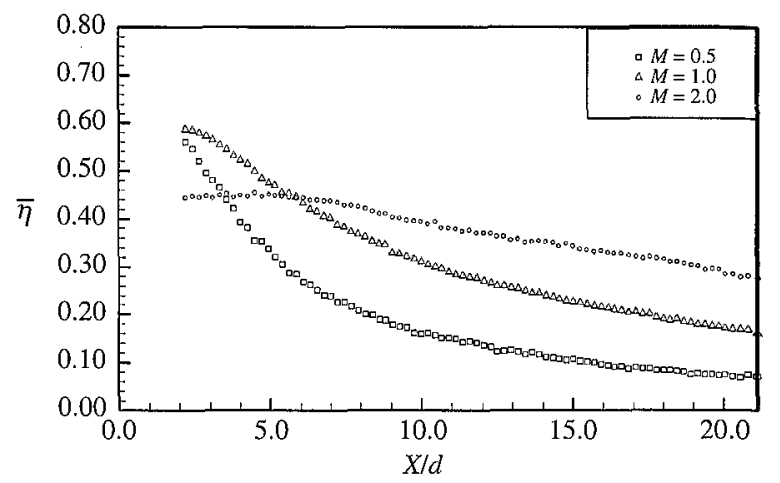

(b) Configuration $\mathrm{C}$

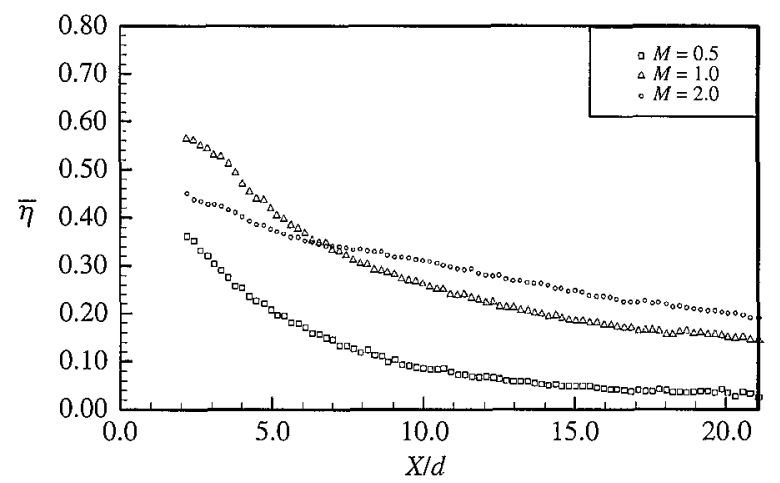

(c) Configuration D

Fig. 6 Streamwise distributions of spanwise averaged film-cooling effectiveness $(\bar{\eta})$ at various blowing ratios: (a) configuration $\mathrm{A}$ and $\mathrm{B}$, (b) configuration $\mathrm{C}$, (c) configuration D

configurations in the whole measured region.

In the Figs. $5(\mathrm{a}, \mathrm{b}, \mathrm{c})$, the $\bar{\eta}$ of configuration $\mathrm{C}$ is higher than the one of configuration $D$ at the same streamwise position $(X / d)$ for the blowing ratio of $0.5,1.0$, and 2.0. The jet flow with $45 \mathrm{deg}$. spanwise ejection angle provides both streamwise and laternal mass flow rate. It causes wider lateral distribution of $\bar{\eta}$ and longer streamwise distribution of $\bar{\eta}$ in comparison with the one with $90 \mathrm{deg}$. spanwise injection angle.

For the hole configuration effect, the spanwise averaged film cooling effectiveness $(\bar{\eta})$ was measured downstream $(X / d)$ from 2.0 to 21.0 at blowing ratios $M=0.5,1.0$ and 2.0, as shown in Figs. $6(\mathrm{a}, \mathrm{b}, \mathrm{c})$. The $\bar{\eta}$ values of configurations $A$ and $B$ increase with 
blowing ratio for $X / d \geq 3.0$ and the $\bar{\eta}$ value of jet flow with compound angle at high blowing ratio of 2.0 is the highest among all the blowing ratios with $0 \mathrm{deg}$. spanwise injection angle, as shown in Fig. 6(a). The $\bar{\eta}$ values of configuration $C$ increase with blowing ratios for $X / d \geq 6.0$ as shown in Fig. 6(b). For $X / d<6.0$, the lift-off effect of jet flow causes values of $\bar{\eta}$ to decay at $M=2.0$. In comparison with Fig. 6(b) and Fig. 6(c), there are similar trends on $\bar{\eta}$ value of configurations $\mathrm{C}$ and $\mathrm{D}$. For configuration $\mathrm{D}$, the variance of $\bar{\eta}$ with blowing ratio from 1.0 to 2.0 is less than that with the blowing ratio from 0.5 to 1.0 , as shown in Fig. 6(c). For the jet flow with 90 degree injection angle, the increase of blowing ratio from 1.0 to 2.0 cannot increase the $\bar{\eta}$ proportionally in comparison with increases when blowing ratio increases from 0.5 to 1.0 . The high blowing ratio of 2.0 gives more lateral jet flow. It causes a stronger collision of the lateral jet flow with the mainstream flow and cannot improve $\bar{\eta}$ obviously.

\section{The Spanwise Averaged Heat Transfer Coeffi- cient $\left(\bar{h} / h_{0}\right)$}

The heat transfer coefficient $(h)$ can be obtained by the theory of liquid crystal thermography ( $\mathrm{Yu}$ et $a l ., 2002)$. The spanwise averaged heat transfer coefficients $\left(\bar{h} / h_{0}\right)$ measured downstream $(X / d)$ from 2.0 to 21.0 at various hole configurations are shown in Figs. 7(a, b, c).

For low blowing ratio of 0.5 , the jet flows are fairly uniform and weak along the wall surface for all configurations. Therefore the value of $\bar{h} / h_{0}$ decreases along the streamwise direction of the mainstream as shown in Fig. 7(a). The close-wall effect of the compound angle injection of configuration $B$ causes the smallest value of $\bar{h} / h_{0}$ for $2 \leq X / d \leq 21.0$. The $\bar{h} / h_{0}$ values of all configurations are fairly constant for $X / d>10.0$ at the blowing ratio of 0.5 . The 45 deg. spanwise injection has wider wall temperature variance region in the lateral direction as shown in Fig. 4(a) and thus gives a higher value of $\bar{h} / h_{0}$ than others near the hole, as shown in Fig. 7(a).

As the blowing ratio is increased to 1.0 , the increasing mass flow rate of the jet flow causes higher values of $\bar{h} / h_{0}$ for $X / d \leq 10.0$, as shown in Fig. 7(b). For $X / d>10.0$, values of $\bar{h} / h_{0}$ are fairly constant and the trend is similar to that at low blowing ratio of 0.5 . The lift-off effect of jet flow causes values of $\bar{h} / h_{0}$ to decay at the near hole region, as if the liftoff effect worked on the $\bar{\eta}$ values. The compound angle injection of configuration $B$ has the smallest value of $\bar{h} / h_{0}$ for $2 \leq X / d \leq 21.0$.

For high blowing ratio of 2.0 , the trend of $\bar{h} / h_{0}$ value is similar to that at $M=1.0$. Comparing Fig. 7(b) and Fig. 7(c), the high blowing ratio of the jet flow causes stronger interaction with the mainstream and thus has a

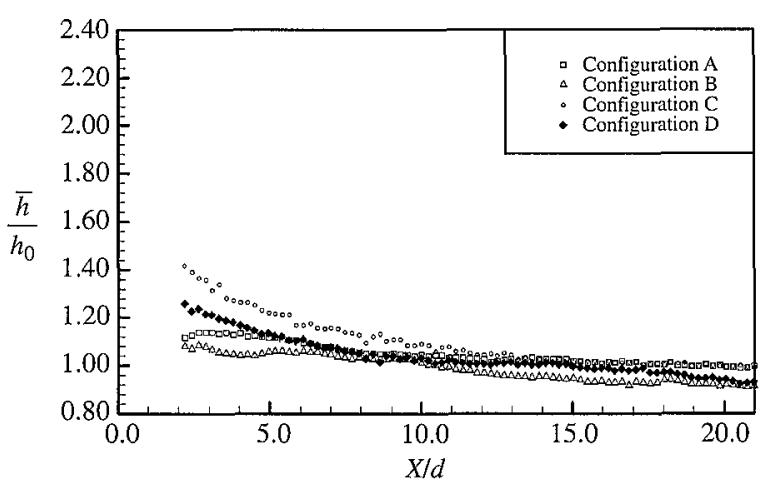

(a) $M=0.5$

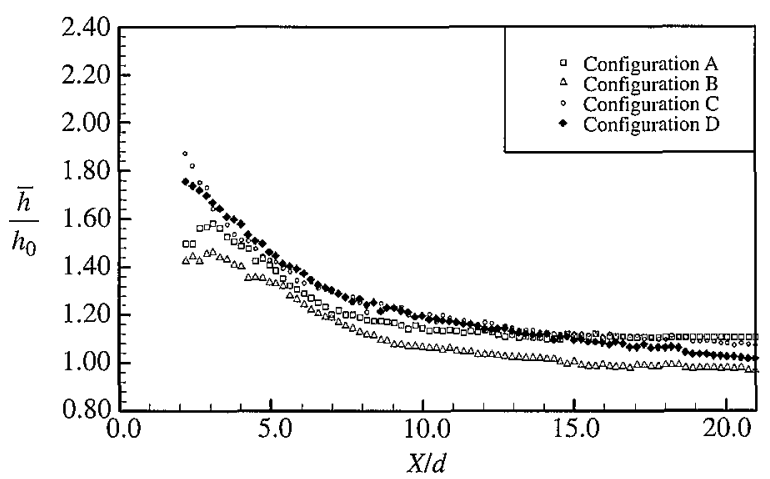

(b) $M=1.0$

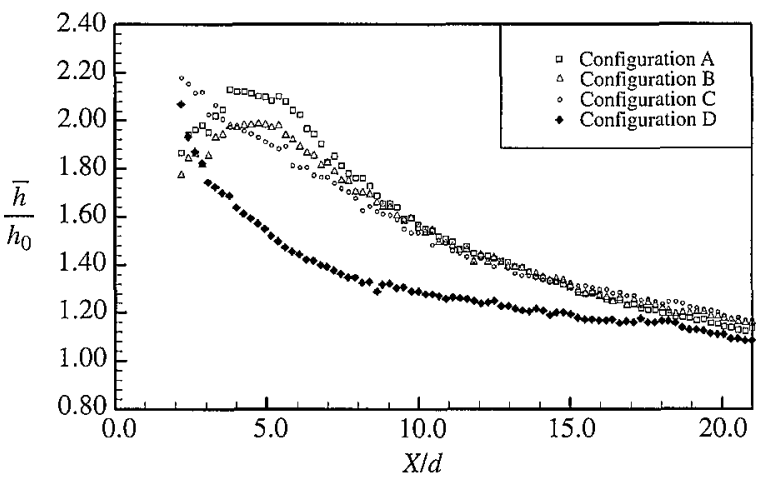

(c) $M=2.0$

Fig. 7 Streamwise distributions of spanwise averaged heat transfer coefficient $\left(\bar{h} / h_{0}\right)$ at various hole configurations: (a) $M=0.5$, (b) $M=1.0$, (c) $M=2.0$

higher $\bar{h} / h_{0}$ value of configuration A, B, and C. For jet flow with $90 \mathrm{deg}$. spanwise angle, the collision of the lateral jet flow with the streamwise mainstream causes a strong interaction and the aerodynamic loss of both flows. Thus the value of $\bar{h} / h_{0}$ is very high in the region close to the hole and decreases steeply along the streamwise direction. And the value of $\bar{h} / h_{0}$ does not obviously raise downstream as the blowing ratio increases from 1.0 to 2.0, as shown in Fig. 7(b) and Fig. 7(c).

\section{Heat Flux Ratio $\left(\bar{q} / q_{0}\right)$}

Determination of heat flux over the tested 
surface requires measured data of both film cooling effectiveness and heat transfer coefficient. Then, the heat flux ratio between surfaces with and without film protection can be expressed as (San et al., 1996; Ekkad et al., 1997b):

$$
\frac{q}{q_{0}}=\frac{h\left(T_{w}-T_{a w}\right)}{h_{0}\left(T_{w}-T_{m}\right)}=\frac{h}{h_{0}}\left(1-\frac{\eta}{\phi}\right)
$$

where $\phi$ is the overall cooling effectiveness defined as $\left(T_{w}-T_{m}\right) /\left(T_{c}-T_{m}\right)$, and $\phi$ is set to 0.6 in the present study. For a typical gas turbine blade with film cooling, $\phi$ ranges from 0.5 to 0.8 .

The average heat flux ratio $\left(\bar{q} / q_{0}\right)$ can be obtained from the average heat transfer coefficient ratio $\left(\bar{h} / h_{0}\right)$ and the average film cooling effectiveness $(\bar{\eta})$. Spanwise averaged heat flux ratios $\left(\bar{q} / q_{0}\right)$ measured downstream $(X / d)$ from 2.0 to 21.0 at various hole configurations are shown in Figs. $8(\mathrm{a}, \mathrm{b}, \mathrm{c})$. Spanwise averaged heat flux ratio $\left(\bar{q} / q_{0}\right)$ is a good indication of the film cooling performance. The compound angle with spanwise injection angle of $0 \mathrm{deg}$. gives the lowest heat flux ratio on the wall surface among all the blowing ratios for $X / d>3.0$ at the blowing ratio of 0.5 , for $X / d>4.5$ at the blowing ratio of 1.0 , and for the whole measured region at the blowing ratio of 2.0, as shown in Figs. 8(a,b, c). For jet flow with $45 \mathrm{deg}$. spanwise angle, the value of $\bar{q} / q_{0}$ is lower than the one of jet flow with $90 \mathrm{deg}$. spanwise angle for the whole measured region at $M=0.5,1.0$, and for $X / d>3.0$ at $M=2$. The jet flow with $90 \mathrm{deg}$. spanwise angle has lower value of $\bar{q} / q_{0}$ and better film cooling performance as the blowing ratio is increased from 0.5 to 1.0 , as shown in Figs. 8(a) and (b). But the jet flow with 90 deg. spanwise angle degrades film cooling performance as the blowing ratio is increased from 1.0 to 2.0 for $X / d<7.5$, as shown in Figs. 8(b) and (c). The reason is that the collision of the lateral jet flow with the streamwise mainstream causes a stronger interaction and thus has higher value of $\bar{h} / h_{0}$ and lower $\bar{\eta}$ in the near hole region.

\section{CONCLUSIONS}

The influences of blowing ratio, staggered rows arrangement, compound angle, and injection angle orientation on film cooling performance over a concave surface are investigated. Transient liquid crystal thermography is used to measure the film cooling performance for two staggered rows of holes with $\gamma=35^{\circ}$. Results are presented for $M=0.5,1.0$, and 2.0 , and $\beta$ $=0^{\circ}, 45^{\circ}$, and $90^{\circ}$. The following is a summary of conclusions.

1. The jet flow with $M=0.5$ is fairly uniform along the wall surface such that the $\eta$ is relatively high

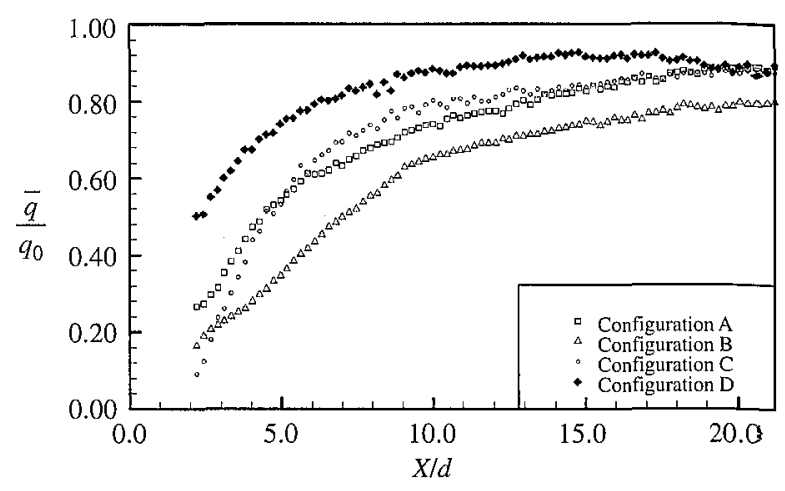

(a) $M=0.5$

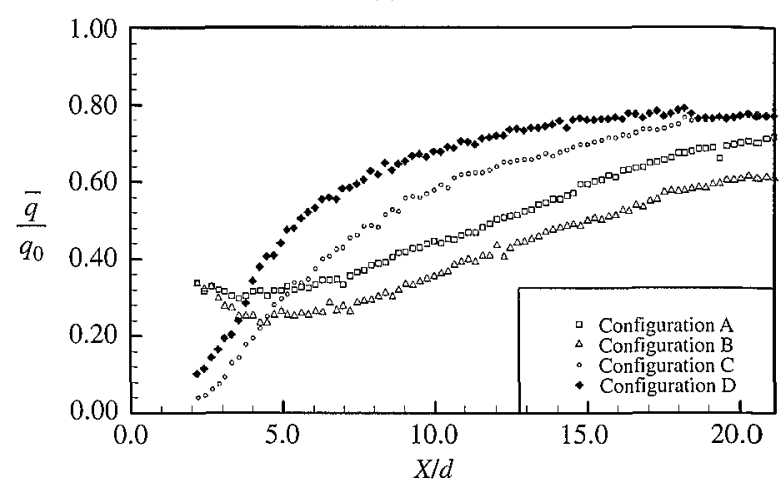

(b) $M=1.0$

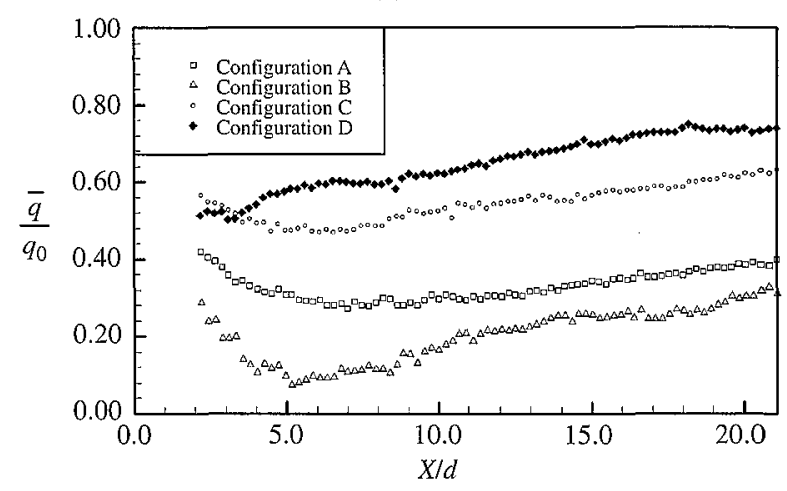

(c) $M=2.0$

Fig. 8 Streamwise distributions of spanwise averaged heat flux ratio $\left(\bar{q} / q_{0}\right)$ at various hole configurations: (a) $M=0.5$, (b) $M=1.0$, (c) $M=2.0$

in the near-hole region. At $M=1.0$, the lateral spread-out effect and close-wall effect caused by the compound angle effect are obvious. The liftoff phenomenon can be found in the jet flow with $\beta=0^{\circ}$ for both cases of simple and compound angles at $M=1.0$ and also exists among all test cases at $M=2.0$ except for $\beta=90^{\circ}$.

2. At a fixed blowing ratio, the $\bar{\eta}$ with compound angle is higher than with single angle. The jet flow with compound angle at $M=2.0$ gives the largest $\bar{\eta}$ value of all configurations.

3. The $\bar{h} / h_{0}$ increases with $M$ for all configurations, and decreases along the streamwise direction at 
which the lift-off effect does not occur. The liftoff effect of jet flow results in low values of $\bar{h} / h_{0}$ in the near hole region.

4. The $\bar{q} / q_{0}$ increases along the streamwise direction at which the lift-off effect does not occur. The lift-off effect improves the $\bar{q} / q_{0}$ in the near hole region. At a fixed blowing ratio, the jet flow with compound angle holes has lower $\bar{q} / q_{0}$ than that with simple angle holes. In the present study, the compound angle with $\beta=0^{\circ}$ at $M=2.0$ gives the best film-cooling performance among all the test configurations.

\section{ACKNOWLEDGMENTS}

The authors gratefully acknowledge financial support from the National Science Council of Republic of China through grant NSC86-2212-E-002-080.

\section{NOMENCLATURE}

$c \quad$ jet flow ejected from the injection hole

$d$ injection hole diameter on the inlet plane, [m]

$f \quad$ film cooling

$h$ heat transfer coefficient with film injection, $\left[\mathrm{W} / \mathrm{m}^{2} \mathrm{~K}\right]$

spanwise averaged heat transfer coefficient with film injection using root mean square values of 40 spanwise pixel points, over -5 $\leq X / d \leq 5,\left[\mathrm{~W} / \mathrm{m}^{2} \mathrm{~K}\right]$

$L \quad$ length of injection hole, [m]

$m$ mainstream

$M \quad$ blowing ratio, $M \equiv \rho_{c} u_{c} / \rho_{m} u_{m}$

$o$

$P$

$q$ reference condition (without film injection) pitch of injection holes of one row, [m] heat flux per unit area, $\left[\mathrm{W} / \mathrm{m}^{2}\right]$ spanwise averaged heat flux per unit area, over $-5 \leq X / d \leq 5,\left[\mathrm{~W} / \mathrm{m}^{2}\right]$

radius of curvature of concave surface, $[\mathrm{m}]$ mainstream Reynolds number based on the inlet diameter of injection hole, $=\rho_{m} u_{m} d / \mu$ mainstream turbulence intensity, [\%] surface of test piece axial distance from the center of injection hole of the second row, [m]

spanwise distance from the midpoint of test injection hole, $[\mathrm{m}]$ spanwise injection angle, [deg.] streamwise injection angle, [deg.] adiabatic film cooling effectiveness, $\eta \equiv\left(T_{f}\right.$ $\left.-T_{m}\right) /\left(T_{c}-T_{m}\right)$ spanwise averaged adiabatic film cooling effectiveness using root mean square values of 40 spanwise pixel points, over $-5 \leq$ $X / d \leq 5$

$\mu$

$\rho$ dynamic viscosity of mainstream, $[\mathrm{kg} / \mathrm{ms}]$ density, $\left[\mathrm{kg} / \mathrm{m}^{3}\right]$

\section{REFERENCES}

Berhe, M. K., and Patankar, S. V., 1999, "Investigation of Discrete-Hole Film Cooling Parameters Using Curved-Plate Models," Transactions of the ASME, Journal of Turbomachinery, Vol. 121, No. 4, pp. 792-803.

Chen, P. H., Ai, D., and Lee, S. H., 1998, "Effects of Compound Angle Injection on Flat-Plate Film Cooling through a Row of Conical Holes," ASME Paper, No. 98-GT-459.

Chen, P. H., Ding, P. P., and Ai D., 2001a, "An Improved Data Reduction Method for Transient Liquid Crystal Thermography on Film Cooling Measurements," International Journal of Heat and Mass Transfer, Vol. 44, No. 7, pp. 1379-1387.

Chen, P. H., Hung, M. S., and Ding, P. P., 2001b, "Film Cooling Performance on Curved Walls with Compound Angle Hole Configuration," Heat Transfer in Gas Turbine Systems, Annals of The New York Academy of Sciences, 1st ed., R. J. Goldstein. ed., Vol. 934, pp. 353-360.

Ekkad, S. Zapata, V., D., and Han, J. C., 1997a, "Heat Transfer Coefficients over a Flat Surface with Air and $\mathrm{CO}_{2}$ Injection through Compound Angle Holes Using a Transient Liquid Crystal Image Method," Transactions of the ASME, Journal of Turbomachinery, Vol. 119, , No. 3 pp. 580-586.

Ekkad, S. V., Zapata, D., and Han, J. C., 1997b, "Film Effectiveness over a Flat Surface with Air and $\mathrm{CO}_{2}$ Injection through Compound Angle Holes Using a Transient Liquid Crystal Image Method," Transactions of the ASME, Journal of Turbomachinery, Vol. 119 pp. 587-593.

Goldstein, R. J., Eckert, E. R. G., and Burggraf, F., 1974, "Effects of Hole Geometry and Density on Three-Dimensional Film Cooling," International Journal of Heat and Mass Transfer, Vol. 17, No. 1 , pp. 595-607.

Goldstein, R. J., and Stone, L. D., 1997, "Rowof-Holes Film Cooling of Curved Walls at Low Injection Angles," Transactions of the ASME, Journal of Turbomachinery, Vol. 119, No. 3, pp. 574-579.

Ireland, P.T., and Jones, T.V., 1987, "The Response Time of a Surface Thermometer Employing Encapsulated Thermochromic Liquid Crystals," Journal of Physics. E: Scientific Instruments, Vol. 20, No. 10, pp. 1195-1199.

Jubran, B., and Brown, A., 1985, "Film Cooling From Two Rows of Holes Inclined in the Streamwise and Spanwise Directions," Journal of Engineering for Gas Turbines and Power, Vol. 107, No. 
1, pp. 84-91.

Kline, S. J., and McClintock, F.A., 1953, "Describing Uncertainties in Single-Sample Experiments," Mechanical Engineering, Vol. 75, No. 1, pp. 3-8.

Ko, S. Y., Yao, Y. Q., Xis, B., and Tsou, F. -K., 1986, "Discrete-Hole Film Cooling Characteristics over Concave and Convex Surfaces," Proceedings of 8th International Heat Transfer Conference, Hemisphere Publishing Corp., San Francisco, CA, USA, Vol. 3, pp. 1297-1301.

Le Brocq, P. V., Launder, B. E., and Priddin, C. H., 1973, "Discrete Hole Injection as a Means of Transpiration Cooling, An Experimental Study," Proceedings of Institution of Mechanical Engineers, Vol. 187, pp. 149-157.

Ligrani, P. M., Wigle, J. Cirisllo, M., S., and Jackson, S. M., 1994, "Film-Cooling From Holes with Compound Angle Orientations: Part 1- Results Downstream of Two Staggered Rows of Holes With 3d Spanwise Spacing," Transactions of the ASME, Journal of Heat Transfer, Vol. 116 pp. 341-352.

Schmidt, D. L., Sen, B., and Bogard, D. G., 1996, "Film Cooling with Compound Angle Holes: Adiabatic Effectiveness," Transactions of the ASME, Journal of Turbomachinery, Vol. 118, No.
4, pp. 807-813.

Schwarz, S. G., and Goldstein, R. J., 1989, "The TwoDimensional Behavior for Film Cooling Jets on Concave Surfaces," Transactions of the ASME, Journal of Turbomachinery, Vol. 111, No. 1, pp. 124-130.

Schwarz, S. G., Goldstein, R. J., and Eckert, E. R. G., 1991, "The Influence of Curvature on Film Cooling Performance," Transactions of the ASME, Journal of Turbomachinery, Vol. 113, No. 3, pp. 472-478.

Sen, B., Schmidt, D. L., Bogard, and D. G., 1996, "Film Cooling with Compound Angle Holes: Heat Transfer," Transactions of the ASME, Journal of Turbomachinery, Vol. 118, No. 4, pp. 800-806.

Yu, Y., Yen, C. H., Shih, T.I.P., Chyu, M. K., and Gogineni, S., 2002, "Film Cooling Effectiveness and Heat Transfer Coefficient Distributions around Diffusion Shaped Holes", Transactions of the ASME, Journal of Heat Transfer, Vol. 124, No. 5, pp. 820-827.

Manuscript Received: May 20, 2004 Revision Received: Nov. 13, 2004 and Accepted: Dec. 07, 2004 